\title{
Research on Fine Management of Construction Cost Based on BIM
}

\author{
Dongbing Huang ${ }^{1, ~ a, ~ Y i n ~ W a n g ~}{ }^{2, b}$ and Jiangmin Zhong ${ }^{3, c}$ \\ ${ }^{1}$ Guizhou University of Finance and economics, Guizhou, China \\ ${ }^{2}$ The class of 2015 Technical Economics and Management majors, Guizhou University of Finance \\ and economics, Guizhou, China \\ ${ }^{3}$ Guizhou University of Finance and economics, Guizhou, China

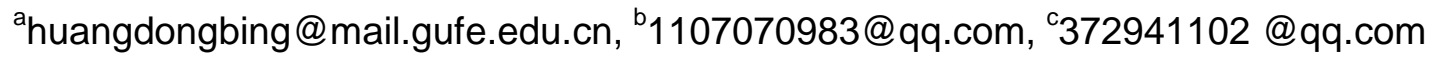

\begin{abstract}
Keywords: BIM; Construction Cost; Fine management
Abstract. BIM is used in the cost of fine management, which is significant to improve the construction cost management.Firstly, the main problems in fine management of construction cost are analyzed deeply. Secondly, the application of the BIM model, in the life cycle of cost management, is explored. Finally, the framework for fine management of construction cost based on BIM is established, and the cost management roadmap is given.
\end{abstract}

\section{Introduction}

Project cost management is the process of project cost forecasting, planning, control, accounting and so on. This process uses a wide range of knowledge, such as: management, economics, engineering and so on [1]. In the different phases of the construction of the project, the project cost management has different work content. The commonality of these work is to effectively control the actual cost of construction projects, reasonable to determine the project cost, and effectively control the project cost, on the basis of reasonably determining the target value of project cost [2].

At present, the engineering technology is changing with each passing day, and the use of new materials is gradually emerging. The management methods are becoming more and more complicated. These changes on the one hand caused the calculation of the project is too cumbersome, and ultimately lead to low accuracy; the other hand, the project cost data is not easy to analyze the use of large, resulting in engineering information can not be shared in time. These problems will affect the effectiveness of the various participants in the project, result in a waste of resources, and reduce the value of construction projects. Adhering to the "Applicable, Economic, Green, Beautiful" architectural guidelines, stricting construction project cost management, the realization of fine management of project cost, which will promote the healthy development of the project cost industry.

\section{Fine Management of Construction Cost}

The Concept of Fine Management of Construction Cost. The fine management of construction cost is to improve the degree of refinement of the various phases of the project cost through the basic principles of precision and strictness, to realize the transition from extensive management to intensive management, from the traditional empirical management to scientific management changes, to ensure that the project cost management fell into the details and practice, to improve the owners of the project investment benefits, to achieve the profit target of construction enterprises and achieve optimal allocation of resources [3].

The Specific Content of Fine Management of Construction Cost. The main goal of fine management of project cost is to enhance the effectiveness of management and correct the problems in cost management. In the project decision phase, design phase, bidding phase, construction phase, completion phase and other refinement phase, from the project cost calculation and control in two aspects, through the use of new technology and new materials, to quickly and accurately determine the project cost, in order to achieve Engineering cost control process refinement, standardization, process, improve cost management efficiency [4]. 
In general, investment estimates should ensure that the design estimates are more accurate than the investment estimates and that the investment estimates guide the design estimates. The construction plan budget is a further refinement of the design budget. The management of the contract price, mainly to communicate and deal with contractors and construction units bidding prices. Prepayment and progress in line with the previous program and construction links. Settlement and final accounts are the control of the various phases of the construction project.

\section{The Main Problems in the Process of Fine Management of Construction Cost}

Design Phase. During the design phase, the project cost management should not only reflect the rationality of the economy but also reflect the advanced nature of the design. However, in the general case, budgetary estimates during the design phase is only the result of the limited set of budget estimates. The budget of the construction plan is due to the urgency of time, which leads to the lack of sufficient amount, artificial, material, mechanical prices lack of timeliness, and finally can not accurately evaluate the design. In the design phase, different professions can not be accurately examined, this professional collision will also have an impact on the late changes.

Bidding Stage. During the bidding phase, the sub-project is not accurate calculation of the amount. On the one hand this will affect the actual size of the construction project, on the other hand a huge amount of engineering bias will allow bidders to take advantage of the unbalanced offer. The depreciation of the control price is often based on the industry does not have the time limit, and more difficult to obtain accurate market information, which will also affect the tender control price.

Construction Stage. During the construction stage, cost management is often limited to statistics on the projects already under way, or issues a document on the change in the price of the visa change that has occurred, and did not reflect the role of cost management of predictive control. Similarly, in the project implementation stage, the information asymmetry of the participants leds to the information can not be effectively shared, and thus work inefficient.

Completion of the Settlement Phase. The most important job in the completion phase is the audit of the project volume, which has the characteristics of large data, long project cycle, and so on.However, the actual workload of the project is often due to the lack of more effective tools, resulting in time-consuming, heavy workload, low efficiency and other issues. The process of checking the amount of the two sides often appears to calculate the difference, resulting in inefficiency.

\section{Building the Fine Management Framework of Construction Cost Based on BIM}

\section{Design Phase}

(1) Early Collision Detection to Reduce Costs

Project design phase, different specialties establish the corresponding model by BIM, and importe the model into BIM, and then detect the collision of different specialties directly, which improves the efficiency of the management personnel and realizes the collaborative management of different specialties. By early collision detection, the design change can be reduced from the source to reduce the cost.

(2) Collaborative Work of Design and Cost

Cost professionals will importe structure, mechanical and electrical professional BIM model into the BIM software for secondary processing to obtain accurate engineering basic data, and make more manpower and resources for data analysis. Firstly, use the value engineering and other methods to interpret the economic data of the design stage from the economic point of view.Secondly, compare the historical data indicators of similar projects stored by the BIM database. Finally, feedback the final economic indicators to the designer, and select the optimal design. 
(3) BIM - based Construction Cost Management Process

BIM-based cost management in the design phase of the process reflects the participants of the cost of data exchange. The generation, analysis and use of the BIM-based data is conducive to the combination of cost and design, convenient design optimization, cost management in advance. BIM can also detect professional collision, reduce design changes, and achieve cost management goals.

\section{Bidding Stage}

(1) Efficient Preparation of Tender Control Price

Using BIM model to build the BIM project quantity, the tenderer to complete the bill of quantities and the preparation of tender control price. Through the BIM database to compare the finished engineering data to check the validity of the bill of quantities, analyze the composition of the price, to ensure the effectiveness of the tender control price.Precise engineering quantity list and control price reduce the risk of the tenderee.

(2) Using BIM for Bidding

The tenderer through the BIM model provided by the tenderer to review the list of projects, to speed up the process of bidding. The bidder can get the market price through the enterprise BIM, so as to analyze the bidding price, and finally improve the competitiveness of the enterprise.

\section{Construction Stage}

(1) Calculation of Engineering Quantity and Contract Price

With the BIM5D parameterization feature, the original BIM model can be split according to any time period or any construction plane, and the corresponding engineering quantity can be obtained. So the contractor and the contractor can quickly and accurately obtain the BIM database for price information, directly summarize the corresponding stage of the progress of the project price, more efficient to determine the engineering quantity and progress payment of construction cost management during construction stage.

(2) Real-time Tracking of Cost in Formation Data

Project participants according to the specified time, through the BIM model center input accurate cost related information, dynamic real-time maintenance of the relevant cost information, to avoid the loss of data in the construction process.

(3) Dynamic Management of Construction Cost in Construction

First, the project is simulated by the BIM5D model and the engineering quantities are aggregated, using the planned unit price stored in the BIM to form BCWS (planned work budget). Then, in the BIM model, enter the completed project and the actual unit price, the actual project cost (ACWP) and completed project costs (BCWP) can be got, and then use BIM-related software built-in mathematical model to quickly analyze the cost deviation and cost performance index, and ultimately get the most intuitive and accurate comparison results. With the strong support based on BIM, the deviation analysis is no longer limited to the key projects, for each sub-project can be timely access to the results of the deviation analysis. So that the project cost managers have sufficient time to analyze the causes of bias and propose solutions to the deviations.

(4) Changes to the Visa

Entering the information of the visa change into the BIM information center can facilitate the participation of the project participants. Visa changes tend to cause changes in costs, especially for design changes. Entering the information of the visa change into the BIM is conducive to the design, construction, cost of the three parties to compare the program. With BIM, cost managers can calculate the amount of work associated with the change, verify the cost changes caused by the change program, so as to provide economic reference. Tripartite personnel is medium with BIM, and demonstrate the technical, economic and operational characteristics of the scheme, and thus select the optimal program.

(5) The Construction Cost Management Process in Construction Stage Based on BIM

Based on the BIM model established in the design stage, the dynamic construction of BIM mode is established based on the information such as construction period, price and visa change claim, which is based on the dynamic change of the construction and construction stage. This model uses BIM 
technology parameterization and data function to quickly and accurately retrieve the relevant engineering quantity, cost and other data needed for dynamic cost control, and analyze the cost deviation, calculate the cost of visa change, so as to realize the dynamic cost Effective management, to avoid the early stage of the project cost and construction stage of the split-type management model.

\section{Completion of the Settlement Phase}

(1) Audit of Settlement Information

BIM provides a reasonable technology platform for practitioners to integrate the management of engineering data into the project process management, update the engineering information of the BIM central database in real time, participate in accurate and reliable access to relevant engineering information. Retrieve the information in the BIM database according to the duration, or sub-component to improve the efficiency and quality of the settlement project.

(2) Using BIM Technology to Complete the Settlement Project Volume Audit

During the completion of the completion of the settlement period, in the audit of the amount of work, can use the bidding process of engineering three-dimensional model, to directly modify the original design changes. The BIM software can use the Boolean calculation to synchronize the calculation of the amount of engineering of other structural components due to dimensional changes. In addition, BIM can also use the common format file storage under the completion of the map information, to directly import the format to complete the map, and the software can automatically generate the completion of the three-dimensional model and the corresponding amount of information.

(3) The Cost management Process During Completion Settlement Phase

In the completion of the settlement phase, the review of completion settlement is completed by the BIM-related automatic computing function, which is formed by the relevant completion of settlement information obtained from the BIM model and the contents of the contract. Based on the BIM database to fully integrate the implementation of the data in the process, will improve the accuracy of the completion of settlement and reduce the basic work in the completion of settlement drastically, so as to shorten the completion of settlement time.

\section{Conclusions}

The fine management of construction cost is beneficial to the project cost management to achieve refinement, standardization, process. However, in the process of fine management, there are still problems such as low prediction accuracy, slow processing of information processing, rapid change of participant data, and distortion of stage information transmission. The emergence and application of building information model BIM conforms to the development of the construction industry. Based on the building information model, BIM integrates the geometric model information and component function information of the building life cycle, and integrates the information of construction process, such as project progress, engineering cost, operation and maintenance information. It adapts to the different stages of the cost of fine management requirements, avoids the different professional information asymmetry, improves the efficiency of information processing, and provides participants to share data platform, maintenance of information transmission. Therefore, the application of BIM in the fine management of project cost can provide a solution for the implementation of fine management of construction project cost.

\section{References}

[1] Shibo Dong: Research on Cost Management of Life Cycle Engineering(2003) (In Chinese).

[2] Yilin Yin: Pricing and Control of Engineering Cost (2009) (In Chinese).

[3] Yilin Yin: Knowledge of project cost management (2009)(In Chinese).

[4] Xu Yin: Study on the Cost Management of Construction Project in China(2008) (In Chinese). 